\title{
Surrogate Measurement of Chlorine Concentration on Steel Surfaces by Alkali Element Detection via Laser-Induced Breakdown Spectroscopy
}

\author{
X. Xiao ${ }^{\text {a }}$, S. Le Berre ${ }^{a}$, K. C. Hartiga, A. T. Motta ${ }^{a}$, I. Jovanovic ${ }^{a, b}$ \\ ${ }^{a}$ Department of Mechanical and Nuclear Engineering, The Pennsylvania State University, University Park, PA 16802, United States \\ ${ }^{b}$ Department of Nuclear Engineering and Radiological Sciences, University of Michigan, Ann Arbor, MI 48109, United States
}

\begin{abstract}
Chlorine can play an important role in the process of stress corrosion cracking of dry cask storage canisters for used nuclear fuel, which are frequently located in marine environments. It is of significant interest to determine the surface concentration of chlorine on stainless steel canister surface, but measurements are often limited by difficult access and challenging conditions, such as high temperature and high radiation field. Laser-induced breakdown spectroscopy (LIBS) could enable chlorine concentration measurements while meeting the other constraints of this application, but suffers from high excitation energy of chlorine and the interference of the atomic emission lines of iron, thus limiting the sensitivity of detection, especially when LIBS has to be delivered over an optical fiber. We demonstrate that chlorine surface concentrations in the range of $0.5-100 \mathrm{mg} / \mathrm{m}^{2}$ can be inferred by the detection and quantification of sodium contained in chlorine salts if the speciation and neutralization of salts is not of major concern, whereas minor components of sea salt such as magnesium and potassium are less attractive as surrogates for chlorine due to the lower sensitivity of LIBS for their detection and quantification. The limit of detection, measurement accuracy, and other features and limitations of this surrogate measurement approach are discussed.
\end{abstract}

Keywords: laser-induced breakdown spectroscopy, stress corrosion cracking, chlorine, alkali elements PACS: 82.80.-d, 42.62.Fi, 42.62.-b, 52.50.Jm

\section{Introduction}

Dry cask storage systems (DCSS) have been designed to provide interim storage of the used nuclear fuel after its cooling in spent fuel pools at nuclear reactor facilities. DCCS have been widely distributed throughout the United States (U.S.) since the first DCCS license was issued by the Nuclear Regulatory Commission in 1986. Currently, there are over 1500 casks at independent spent fuel storage installations licensed to operate in 34 states in the U.S., about one third of which are located in coastal areas. In those circumstances the casks, comprised of stainless steel (SS) canister and steel-lined concrete overpack, can be exposed to salty and humid marine environment, which creates a potential for stress corrosion cracking (SCC) to occur. SCC is a mechanism whereby cracks can propagate even at a stress intensity factor below the critical level in the presence of an attacking environment provided by chlorine $(\mathrm{Cl})$ ions on the surface, sensitized material, and

Email address: ijov@umich.edu (I. Jovanovic) stress. The heat affected zones of welds may experience tensile residual stress, such that the deliquescence of airborne salts that enter through the cask venting systems could induce SCC of the austenitic SS [1]. Although it can be affected by the environmental conditions, the $\mathrm{Cl}$ concentration on the metal structure of the casks is in the range of $1-100 \mathrm{mg} / \mathrm{m}^{2}\left(0.001-0.1 \mathrm{~g} / \mathrm{m}^{2}\right)$, corresponding to decades of salt deposition, as shown in Japan's field tests [2, 3]. Laser-induced breakdown spectroscopy (LIBS) has been reported to be an effective technique for detecting $\mathrm{Cl}$ on SS surfaces [2, 4]. Features and limitations of this approach must be studied in detail experimentally due to the unique environment in which measurements have to be conducted, which combines the presence of high radiation field, high temperature, and limited access.

LIBS is a method which involves focusing a pulsed laser onto a sample surface to generate a luminous plasma containing ionized and excited particles. Optical emission from the plasma is collected and analyzed spectrally to infer the elemental and isotopic composition of the sample. LIBS has been widely adopted as it 
enables rapid measurement of trace elements with high 94 spatial resolution and minimal destruction [5-7]. LIBS represents a promising technique for in-situ analysis of the concentration of chlorine attached to the SS canister with no need of sample preparation when compared to other traditional post mortem methods, such as electric conductivity measurement, atomic absorption spec- 100 trometry, and ion chromatography [2-4]. LIBS can be ${ }_{101}$ used to analyze samples with a limited degree of rough- 102 ness and even with cracks, as long as the sampled spot ${ }_{103}$ size is larger than the crack width [8].

The analytical performance of the LIBS technique 105 strongly depends on the choice of experimental param- 106 eters, including the laser wavelength and fluence, pulse ${ }_{107}$ duration, pulse shape, ambient gas and pressure, sam- 108 ple surface morphology and temperature, and the de- 109 tailed geometry of the experimental setup. LIBS has 110 been extensively studied and optimized in the past, such 111 that the limit of detection (LOD) of trace elements has 112 been greatly improved as a result of the significant en- 113 hancement of the signal-to-noise ratio of the emission 114 lines [4-7, 9-12]. LIBS measurements of $\mathrm{Cl}$ attached 115 to SS are challenging due to the high excitation energy 116 of $\mathrm{Cl}(10.4 \mathrm{eV})$, low atomization level in the plasma, 117 and the interference of intense atomic emission lines of 118 iron in the region of interest, especially when quantita- 119 tive concentration measurements are sought at low con- 120 centrations and when LIBS has to be delivered over an 121 optical fiber [4, 13].

One possible alternative to this approach is to use the ${ }_{123}$ detection of alkali metals as a surrogate to infer the pres- 124 ence of salt (and thus, Cl), assuming that the concentra- 125 tion of these metals is proportional to that of Cl. Prior 126 studies have shown that the ratio of alkali metals, such ${ }_{127}$ as $\mathrm{Na}, \mathrm{Mg}$, and $\mathrm{K}$, to $\mathrm{Cl}$ in most of the oceans and major ${ }_{128}$ seas has no significant variation within the limit of ana- 129 lytical error of the ion exchange method $[14,15]$. How- ${ }_{130}$ ever, potential $\mathrm{Cl}$ depletion during the transport and de- 131 position of sea salt aerosols in polluted coastal environments and in biogenic sulfuric acid atmosphere could occur as a consequence of $\mathrm{pH}$-lowering reactions with atmospheric acids, leading to the volatilization of $\mathrm{Cl}$ as $\mathrm{HCl}$. [16, 17].

Typical LOD of a few ppm for metallic elements can ${ }_{135}$ be achieved in LIBS [18], and if alkali metals are de- ${ }_{136}$ tected at concentrations that suggest the presence of ${ }_{137}$ a significant concentration of $\mathrm{Cl}$, more detailed direct ${ }_{138}$ measurements of $\mathrm{Cl}$ could be performed. In order to 139 use alkali elements as surrogates for $\mathrm{Cl}$, it is necessary 140 to fully understand the transport and deposition mech- 141 anism of $\mathrm{Cl}$ and alkali elements. It is also necessary to 142 investigate other possible sources of alkali metals such 143 as dust, which could generate false positives. Nevertheless, this measurement approach appears to be a promising path to use LIBS on SS while avoiding the concerns of the interference from $\mathrm{Fe}$, reduce LOD, reduce the laser pulse energy needed for the measurement, reduce the potential detrimental effect of laser ablation, enable measurements with simpler, single-pulse lasers rather than double-pulse lasers, and enable fiber-coupled LIBS for field deployment.

In this study, standardized procedures have been developed to prepare samples for LIBS measurements. A nebulizer was used to deposit synthetic seawater on heated $(500 \mathrm{~K}) \mathrm{SS}$ at several $\mathrm{Cl}$ surface concentrations below $100 \mathrm{mg} / \mathrm{m}^{2}$. These samples were analyzed by LIBS at room temperature in air in the wavelength region of $\mathrm{Na} \mathrm{I}, \mathrm{Mg} \mathrm{I}, \mathrm{K} \mathrm{I}$, and $\mathrm{Cl}$ I lines and benchmarked by scanning electron microscopy (SEM), energy dispersive X-ray spectroscopy (EDS), and ion chromatography (IC) techniques. SEM/EDS/IC results and LIBS spectra show high homogeneity achieved in sample preparation, feasibility of quantification of $\mathrm{Cl}$ deposited on SS in the concentration range of $0.5-100 \mathrm{mg} / \mathrm{m}^{2}$ by means of surrogate alkali element measurement in laboratory conditions (primarily by $\mathrm{Na}$ and possibly by $\mathrm{Mg}$ and $\mathrm{K}$ with improved sensitivity), and the practical potential of being integrated into a fiber-coupled LIBS system for application in field environment. Thus, the work presented here will be relevant for measuring and quantifying $\mathrm{Cl}$ concentrations if in fact the $\mathrm{Na}$ and $\mathrm{Cl}$ concentration correlate well (i.e. if there is little speciation during transport and deposition on the canisters). Direct LIBS measurement of $\mathrm{Cl}$ concentration is also presented to increase the confidence in the results of surrogate measurement, but the high laser intensity on the sample achieved in this open-beam delivery configuration will be difficult to obtain in LIBS with fiber delivery, thus limiting the LOD and even hindering the direct observation of $\mathrm{Cl}$.

\section{Experimental Setup and Methods}

In our experiment, a frequency doubled Q-switched Nd:YAG laser (Spectra Physics Quanta-Ray PRO-25010) with pulse duration of $\sim 10 \mathrm{~ns}$ and a repetition rate of $10 \mathrm{~Hz}$ was used. The second-harmonic pulses at a wavelength of $532 \mathrm{~nm}$ were attenuated to $\sim 40 \mathrm{~mJ}$. Laser pulses were focused using a plano-convex lens with a focal length of $300 \mathrm{~mm}$. The spot diameter on the sample surface, determined by the resulting laser ablation crater shown in SEM results, was approximately $200 \mu \mathrm{m}$. A 3-axis travel translation stage was used to provide precise motion control of the sample to expose 
a "fresh" point on the surface of the sample when re- 177 quested. Repeated measurements of different spots on 178 the sample surfaces were performed for surface averag- 179 ing.

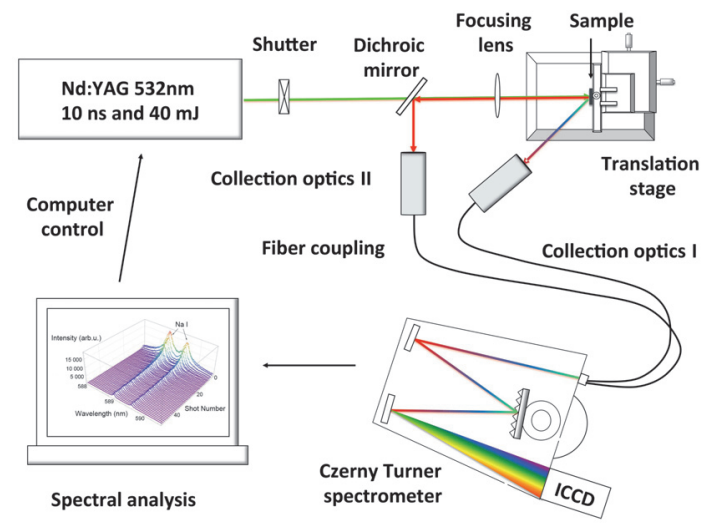

Figure 1: Experimental setup for LIBS measurement with open-beam delivery.

As shown in Fig. 1, the light emitted from the plasma was collected in standard atmospheric conditions by a $50-\mathrm{mm}$ focal length lens positioned at $45^{\circ}$ with respect to the incident beam for measurement of $\mathrm{Na} \mathrm{I}(589 \mathrm{~nm})$, Mg I (518 nm), and K I (766 nm) emission (collection optics I). The Na I $(819 \mathrm{~nm})$ and $\mathrm{Cl}$ I $(837.6 \mathrm{~nm})$ emission were collected in a coaxial configuration (collection optics II), in which a dichroic mirror passed the $532 \mathrm{~nm}$ light and reflected the light with wavelengths greater than $800 \mathrm{~nm}$. A long pass filter with a cutoff near $600 \mathrm{~nm}$ was placed in front of the $50 \mathrm{~mm}$ collection lens to eliminate the second-order diffraction of the iron lines 192 in the region near $400 \mathrm{~nm}$. The light coupled into the 193 400- $\mu \mathrm{m}$ diameter quartz fiber was diverted into a Horiba 194 Jobin Yvon iHR550 Czerny-Turner spectrometer with 195 1200 and 1800 grooves/mm gratings and an Andor iStar 196 $334 \mathrm{~T}$ intensified charge-coupled device (ICCD). The 197 spectrometer was calibrated using an Ocean Optics DH- 198 2000 light source. A LabVIEW-based data acquisition 199 system was developed to provide proper timing between 200 the mechanical shutter and the ICCD camera through 201 a Stanford Research Systems DG645 delay generator, 202 such that the shutter allowed the desired number of laser 203 shots to pass through and the camera recorded the data 204 with a set gate width and gate delay referenced to the 205 laser pulse. The reported spectra represent an accumu- 206 lation of two laser ablations for each spot at several dif- 207 ferent locations spaced at least $1.25 \mathrm{~mm}$ apart to account 208 for the transition area of the neighboring spot. The ex- 209 perimental parameters, including the laser pulse energy, the gate delay, and the gate width, were kept identical for analysis of each element, whereas the gain applied to the ICCD was varied and later calibrated.

\section{Results and Discussion}

\subsection{Sample preparation and characterization}

The standard samples used for calibrating LIBS measurements, i.e. determining the relationship between characteristic line emission intensity and areal concentration, were prepared using a PerkinElmer Mira-mist nebulizer (P/N N0775330). Nanoscale aerosol particles were created by the nebulizer by combining the diluted synthetic seawater with an inert gas (argon), which was used as a transporter. The composition of the synthetic seawater is shown in Table 1.

Table 1: Composition of synthetic seawater (Lake Products Company LLC)

\begin{tabular}{lc}
\hline Components & Concentration $(\mathbf{g} / \mathbf{L})$ \\
\hline $\mathrm{NaCl}$ & 24.53 \\
$\mathrm{MgCl}_{2}$ & 5.20 \\
$\mathrm{Na}_{2} \mathrm{SO}_{4}$ & 4.09 \\
$\mathrm{CaCl}_{2}$ & 1.16 \\
$\mathrm{KCl}$ & 0.695 \\
$\mathrm{NaHCO}$ & 0.201 \\
$\mathrm{KBr}$ & 0.101 \\
$\mathrm{H}_{3} \mathrm{BO}_{3}$ & 0.027 \\
$\mathrm{SrCl}$ & 0.025 \\
$\mathrm{NaF}$ & 0.003 \\
$\mathrm{Total}$ & 36.032 \\
\hline
\end{tabular}

When dried at room temperature (RT), aerosol particles aggregate on the surface of the SS substrates and form crystals much larger than the diameter of the spraying aerosol. More homogeneous salt distribution could be observed when aerosols were deposited on heated $(\sim 500 \mathrm{~K})$ surfaces due to the instant vaporization of the water on contact with the surface. A Thermo Scientific Cimarec hot plate was used to preheat the SS substrates. Samples were removed from the hot plate before spraying the salt water because we noticed that the natural convection above the hot plate impacts the salt deposition. The exposure time was limited to $1 \mathrm{~min}$ to avoid significant cooling down of the substrates. Reheating of these substrates was required for longer spraying time. The experimental setup for sample preparation is shown in Fig. 2.

Two sets of samples $\left(25 \times 25 \mathrm{~mm}^{2}\right)$ with $\mathrm{Cl}$ surface concentration of $0.5-100 \mathrm{mg} / \mathrm{m}^{2}$ and $2.5-25 \mathrm{mg} / \mathrm{m}^{2}$ 


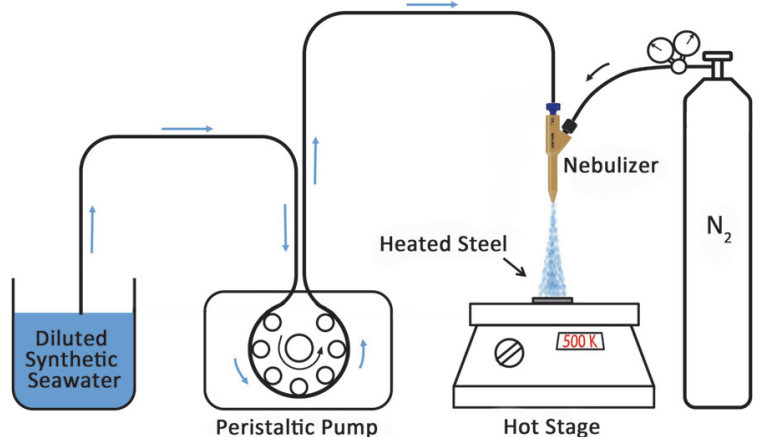

Figure 2: Experimental setup for sample preparation using PerkinElmer Mira Mist nebulizer (P/N:N0775330). were prepared. These concentrations were calculated from the concentration of the diluted seawater solution, the known well-controlled flow rate of the nebulizer, the exposure time of the samples, and the sprayed sample area. The volumetric flow rate of the nebulizer was $0.25 \mathrm{~mL} / \mathrm{min}$. The nebulizer was placed $15 \mathrm{~cm}$ above the sample, and the spraying area was measured to be $16 \mathrm{~cm}^{2}$. The dilution factor was selected to be $1 / 100$, except for the concentrations of $0.5 \mathrm{mg} / \mathrm{m}^{2}$ and $1 \mathrm{mg} / \mathrm{m}^{2}$, where a 1/1000 dilution factor was used.

Fig. 3 shows the SEM images of samples prepared in this fashion. At RT we observe salt crystals with an average diameter of $\sim 50 \mu \mathrm{m}$ uniformly spread over the $\mathrm{SS}$ substrate at $\mathrm{Cl}$ concentration of $3 \mathrm{~g} / \mathrm{m}^{2}$ (Fig. 3 (a)), whereas a continuous film of salt is observed on the 246 heated $100 \mathrm{mg} / \mathrm{m}^{2}$ substrate, as shown in Fig. 3 (b). 247 Fig. 3 (b-e) shows the salt distribution for $\mathrm{Cl}$ concentra- 248 tions spanning two orders of magnitude, from $5 \mathrm{mg} / \mathrm{m}^{2} \quad 249$ to $100 \mathrm{mg} / \mathrm{m}^{2}$. The salt deposit patterns on the lower 250 concentration samples are regular and form shapes cor- 251 responding to the spraying pattern of the nebulizer. The 252 presence of the salt, homogeneity over the scale of the 253 focal spot size, and relative salt concentrations of the 254 samples were confirmed using EDS. Such samples pre- 255 pared using the nebulizer, even when prepared at RT, 256 show higher homogeneity than the liquid-dried samples 257 and thus have been chosen to serve as standards for 258 LIBS measurements.

A typical area affected by laser ablation on a sample 260 with $25 \mathrm{mg} / \mathrm{m}^{2} \mathrm{Cl}$ concentration can be seen in Fig 3 (f). ${ }_{261}$ The ablation crater presents a high degree of geometri- 262 cal reproducibility. The $200 \mu \mathrm{m}$ diameter crater is di- 263 rectly surrounded by a depleted area $\sim 600 \mu \mathrm{m}$ in diam- 264 eter, on which no salt is detected by EDS, and by a ther- 265 mally affected area of $\sim 6 \mathrm{~mm}$ diameter, in which the 266 salt layer is visibly modified, probably due to melting 267

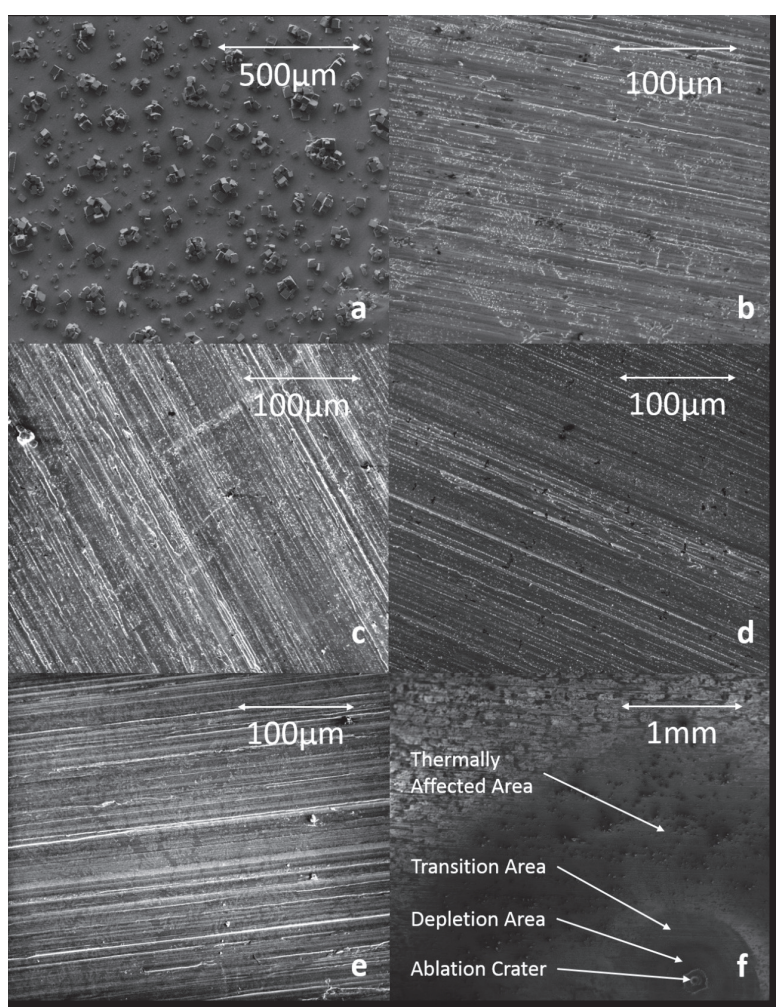

Figure 3: SEM images of prepared samples: (a) unheated $3 \mathrm{~g} / \mathrm{m}^{2}$; (b) heated $100 \mathrm{mg} / \mathrm{m}^{2}$; (c) heated $50 \mathrm{mg} / \mathrm{m}^{2}$; (d) heated $25 \mathrm{mg} / \mathrm{m}^{2}$; (e) heated $5 \mathrm{mg} / \mathrm{m}^{2}$; (f) The various affected areas in the vicinity of the ablation spot. (FESEM: NanoSEM 630)

under the high substrate temperature induced by the deposition of the laser energy. EDS analysis also showed that the salt concentration in the thermally affected area was not different from that of the unperturbed salt layer, as shown in Fig. 3. A transition area of $\sim 1.25 \mathrm{~mm}$ diameter is observed between the depleted and thermally affected areas, within which a gradient of concentration could be measured. This led us to set the spacing between the measured spots to be at least $1.25 \mathrm{~mm}$, so that each new measurement is made outside of the transition area of prior laser ablations and the concentration of $\mathrm{Cl}$ is not affected at the position of the new laser plasma.

Surface concentrations in $\mathrm{Cl}$ and alkali elements were first investigated using SEM-EDS to characterize their homogeneity and the composition of salt layers (constant stoichiometry between $\mathrm{Cl}$ and $\mathrm{Na}$ ). To confirm the absolute concentrations, we used ion chromatography (IC), which is a quantitative measurement method for anions in liquid phase. After sample preparation, samples from a given batch were immersed into deionized water inside a micro-cleanser to dissolve their salt layer. The liquid solution was then analyzed with ion chro- 
matography to obtain the surface concentrations. Fig. 4296 shows the results we obtained for samples with chlo- 297 rine concentrations in the range of $0.7-140 \mathrm{mg} / \mathrm{m}^{2}$. The 298 good agreement between the calculated and the experi- 299 mentally measured chlorine concentration confirms that 300 calculated concentrations are indeed representative of 301 actual concentrations.

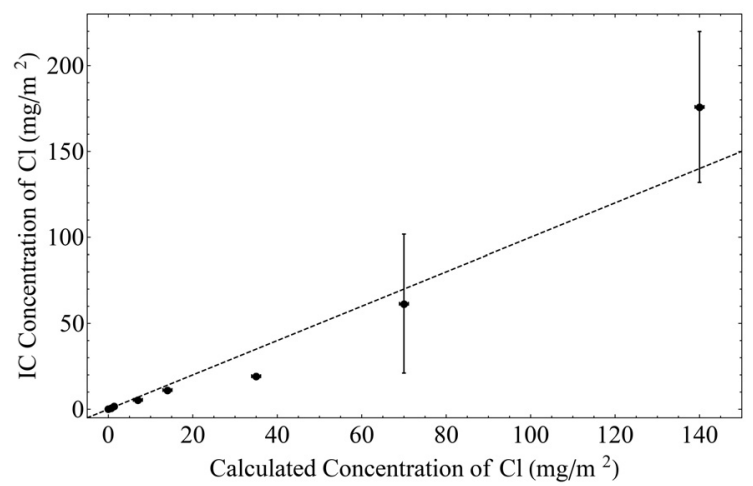

Figure 4: Dependence of the $\mathrm{Cl}$ concentration measured by ion chromatography (IC) on the calculated $\mathrm{Cl}$ concentration in the range of $0.7-140 \mathrm{mg} / \mathrm{m}^{2}$. The dashed line represents a perfect agreement between the calculated and the measured $\mathrm{Cl}$ concentration, whereas the ${ }^{319}$ solid circles are the experimental data. The vertical error bars repre- 320 sent the standard deviation of the $\mathrm{Cl}$ concentration measured by IC ${ }_{321}$ with two sets of samples. The horizontal error bars originate from 3-s timing uncertainty in the sample preparation process.

\subsection{Spectral analysis for quantification of sea salt con- 3} centration on stainless steel

\subsubsection{Na I emission line at $589 \mathrm{~nm}$}

Fig. 5 (a) shows the $\mathrm{Na}$ emission spectra in the spec- 330 tral range of 587.0-591.5 $\mathrm{nm}$ at $\mathrm{Na}$ concentrations of ${ }_{331}$ $0.28-55 \mathrm{mg} / \mathrm{m}^{2}$, corresponding to $\mathrm{Cl}$ concentration of ${ }_{332}$ $0.5-100 \mathrm{mg} / \mathrm{m}^{2}$. Spectral emission of the hyperfine-split $\mathrm{Na} D$ lines at $589.0 \mathrm{~nm}\left(\mathrm{D}_{2}\right.$ line: $\left.3 p^{2} \mathrm{P}_{3 / 2}^{\mathrm{o}} \rightarrow 3 s^{2} \mathrm{~S}_{1 / 2}\right){ }_{334}$ and $589.6 \mathrm{~nm}\left(\mathrm{D}_{1}\right.$ line: $\left.3 p{ }^{2} \mathrm{P}^{\mathrm{o}}{ }_{1 / 2} \rightarrow 3 s^{2} \mathrm{~S}_{1 / 2}\right)$ has been ${ }_{335}$ measured with a gate delay and a gate width time of ${ }_{336}$ the ICCD camera of $1 \mu \mathrm{s}$ and $0.1 \mu \mathrm{s}$, respectively, to ${ }_{337}$ avoid strong self-reversal effect and alleviate spectral 338 line broadening of $\mathrm{Na}$ emissions. The doublet peaks 339 increase and broaden with the increase of Na concen- 340 tration, corresponding to increased electron density and 341 temperature. No significant environmental background 342 $\mathrm{Na}$ emission could be detected from the spectrum mea- 343 sured on a blank SS substrate. The emission spectra 344 were averaged over 20 different locations of the sam- 345 ple with accumulation of two laser pulses on each spot. 346 Multiple peak fitting with Lorentz distributions were 347 used for spectral analysis. The $\mathrm{Na} \mathrm{D}_{2}$ line was used for quantification.

The dependence of the emission intensity of the $\mathrm{Na} \mathrm{D}_{2}$ line on calculated $\mathrm{Na}$ concentration in the range of $0.28-55 \mathrm{mg} / \mathrm{m}^{2}$ is shown in Fig. 5 (b). An exponential relationship is fitted between the calculated $\mathrm{Na}$ concentrations and the mean values of intensity of the $\mathrm{D}_{2}$ line to account for self-absorption of $\mathrm{Na}$ I emission [2]. The self-absorption effect is prominent for the $\mathrm{Na} \mathrm{D}$ lines when the plasma is optically thick, which not only reduces the peak intensity, but also causes the observed line broadening [19]. As a result, the linear dynamic range of this resonance line is limited to $\lesssim 20 \mathrm{mg} / \mathrm{m}^{2}$, but it still extends about two orders of magnitude down to $0.28 \mathrm{mg} / \mathrm{m}^{2}$ with high sensitivity. The error bars of the $\mathrm{Na}$ emission intensity are primarily due to the assumed Gaussian-shaped spraying distribution of the nebulizer and the variability of the emission intensity (error bars of the lowest two data points are too small to be observed in Fig. 5 (b)). The estimated timing uncertainty of $3 \mathrm{~s}$ in sample preparation process is the only contribution to the error bars for the calculated concentration. Because of the one order-of-magnitude difference in dilution of the sea salt solution used, data points with $\mathrm{Na}$ concentrations below $0.6 \mathrm{mg} / \mathrm{m}^{2}$ have a much smaller standard deviation of the calculated concentration of $\mathrm{Na}$; this standard deviation is too small to be displayed in Fig. 5 (b). A good correlation of the measured $\mathrm{Na}$ emission intensity with the calculated $\mathrm{Na}$ concentration is found with a $R^{2}=0.94$, suggesting that the measurement of $\mathrm{Na}$ can be a good surrogate for the measurement of salt concentration in laboratory environment, in which the Cl-to-Na ratio remains approximately constant during the deposition process in sample preparation.

Rapid environmental reactions with atmosphere pollutants, mainly $\mathrm{SO}_{2}, \mathrm{H}_{2} \mathrm{SO}_{4}$, and $\mathrm{HNO}_{3}$, may occur during transport and deposition of sea salt aerosol particles, which leads to degassing of $\mathrm{HCl}$ and loss of $\mathrm{Cl}$. Consequently, sodium nitrate and sodium sulfate are frequently observed as a surface coating of sea salt particles [16]. The potential change of Cl-to-Na ratio caused by this neutralization of sea salt aerosol particles would compromise the use of alkali elements as surrogates of $\mathrm{Cl}$ in LIBS measurements, unless this reaction process is well understood and characterized. In spite of this effect, the surrogate measurement by Na via LIBS technique can still be used to reduce the false negative rates in $\mathrm{Cl}$ detection, since it is a much more sensitive approach than the direct measurement of $\mathrm{Cl}$ on SS by LIBS. This is primarily the result of the low excitation energy of $\mathrm{Na}$ and the avoidance of significant interfer- 

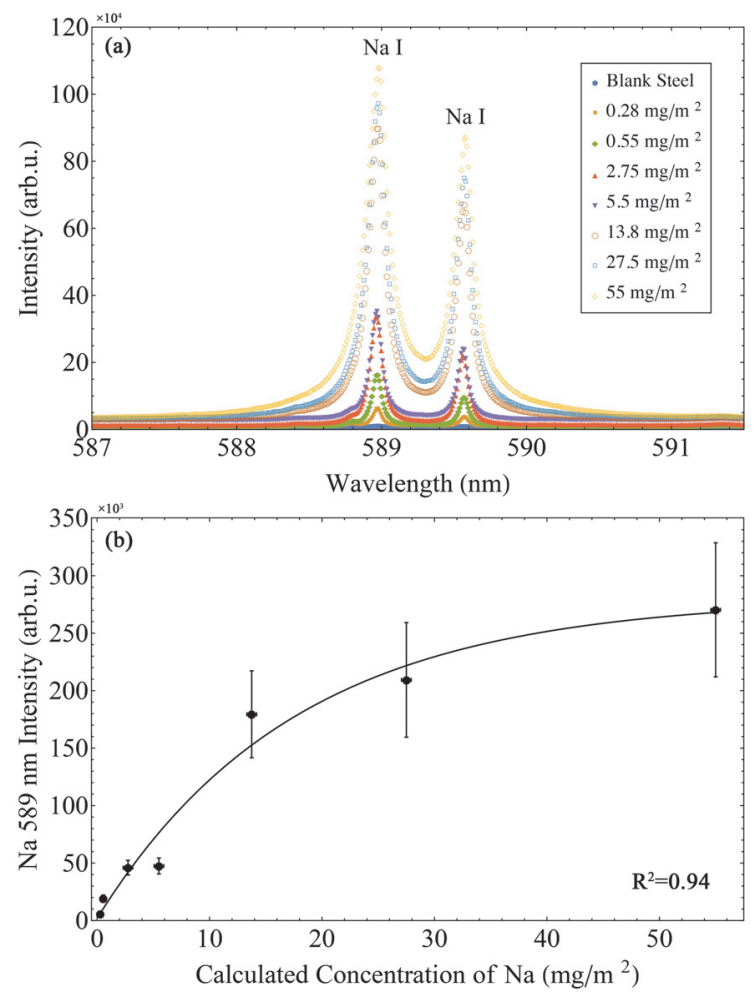

Figure 5: (a) Na I accumulated emission spectrum (20 position aver- 387 aged) of SS samples with Na concentrations in the range of $0.28-388$ $55 \mathrm{mg} / \mathrm{m}^{2}$ and the background spectrum of a blank SS substrate; 389 (b) dependence of the $\mathrm{Na}$ I $(589.0 \mathrm{~nm})$ emission intensity (peak area) on calculated $\mathrm{Na}$ concentration in the range of $0.28-55 \mathrm{mg} / \mathrm{m}^{2}$. The corresponding $\mathrm{Cl}$ concentration is in the range of $0.5-100 \mathrm{mg} / \mathrm{m}^{2}$. The 391 solid line is exponential fit of the experimental data (solid circles). 392 The vertical error bars represent the standard deviation of the emission intensities at 20 positions. The horizontal error bars originate from 3-s timing uncertainty in the sample preparation process. For interpretation of the references to color in this figure legend, the reader 395 is referred to the web version of this article.

$$
90
$$

ence with $\mathrm{Fe}$ lines. Due the the significant reduction of the required laser intensity, surrogate LIBS measurement of $\mathrm{Cl}$ using $\mathrm{Na}$ is desirable for simple fiber delivery configurations and is a promising path for practical use in DCSS.

\subsubsection{Other emission lines from $\mathrm{Na}, \mathrm{K}$, and $\mathrm{Mg}$}

The set of samples used in experiments described in 405 Sections 3.2 .2 and $3.2 .3 \mathrm{had} \mathrm{Cl}$ conctions range of $2.5-25 \mathrm{mg} / \mathrm{m}^{2}$. The $\mathrm{Na} / \mathrm{Cl}, \mathrm{Mg} / \mathrm{Cl}$, and $\mathrm{K} / \mathrm{Cl} 407$ mass ratios in artificial sea water are $0.55,0.07$, and ${ }_{408}$ 0.02 , respectively, from which the concentrations of $\mathrm{Na}, 409$ $\mathrm{Mg}$, and $\mathrm{K}$ are calculated. We assumed that these ra- 410 tios were constant during the short transport time in our ${ }_{411}$ laboratory environment. The emission spectra of $\mathrm{Na}$ I ${ }_{412}$
( 819 nm), Mg I (518.4 nm), K I (766.4 nm), and Cl I $(837.6 \mathrm{~nm})$ were averaged at five different locations.

Another $\mathrm{Na}$ doublet at $818.3 \mathrm{~nm}$ $\left(3 d{ }^{2} \mathrm{D}_{3 / 2} \rightarrow 3 p \quad{ }^{2} \mathrm{P}^{\mathrm{o}}{ }_{1 / 2}\right)$ and $819.5 \mathrm{~nm}$ $\left(3 d{ }^{2} \mathrm{D}_{5 / 2} \rightarrow 3 p{ }^{2} \mathrm{P}_{3 / 2}^{\mathrm{o}}\right)$ have also been measured using a $2-\mu$ s gate delay and $10-\mu$ s gate width. The $\mathrm{Na}$ I line at $819.5 \mathrm{~nm}$ was quantified using a Lorentz fit. Fig. 6 (a) shows the calibration curve for the intensity of Na I line at $819.5 \mathrm{~nm}$. This calibration curve is linearly proportional to $\mathrm{Na}$ concentration within the range of $0.14-13.8 \mathrm{mg} / \mathrm{m}^{2}$. The effect of self absorption of this $\mathrm{Na}$ line is less significant due to the transition to an excited state (3p) and to the low Na concentration. Therefore, a linear model was used to fit the mean $\mathrm{Na}$ I emission intensity at $819.5 \mathrm{~nm}$, obtaining a good correlation between the intensity and the concentration with a $R^{2}=0.92$.

$\mathrm{Mg}$ and $\mathrm{K}$ were investigated as other potential surrogates for $\mathrm{Cl}$ measurement. The $\mathrm{Mg} \mathrm{I}$ line at $518.4 \mathrm{~nm}$ was measured using a gate delay of $2 \mu$ s and gate width of $10 \mu \mathrm{s}$, while for the $\mathrm{K}$ I line at $766.4 \mathrm{~nm}, 0.5-\mu \mathrm{s}$ delay and 5- $\mu \mathrm{s}$ width were used. Since $\mathrm{Mg}$ and $\mathrm{K}$ are minor components in the sea salt solution and both emission lines overlap with intense $\mathrm{Fe}$ and/or Ar lines, the sensitivity of LIBS based on these surrogate elements is limited. Figs. 6 (b) and (c) show the dependence of $\mathrm{Mg}$ I and K I intensity on the calculated Mg and K concentrations in the ranges of $1.4-13.8 \mathrm{mg} / \mathrm{m}^{2}$ and $0.05-$ $0.5 \mathrm{mg} / \mathrm{m}^{2}$, respectively. Relatively poor correlation of the linear fits $\left(R^{2}=0.68\right.$ for $\mathrm{Mg}$ and $R^{2}=0.72$ for $\left.\mathrm{K}\right)$ have been obtained, indicating that the measurement of $\mathrm{Mg}$ and $\mathrm{K}$ are not the ideal surrogates for the measurement of $\mathrm{Cl}$ at such low concentrations in current experimental conditions.

\subsubsection{Cl I emission line at $837.6 \mathrm{~nm}$}

Fig. 7 (a) shows the emission spectra in which several $\mathrm{Cl}$ emission lines belonging to multiplet of $4 p^{4} \mathrm{D}^{\mathrm{o}} \rightarrow 4 s^{4} \mathrm{P}$ can be observed in the spectral range of 830.8-844 $\mathrm{nm}$ when a gate delay of $0.5 \mu$ s and gate width of $5 \mu$ s are used. The $\mathrm{Cl}$ I line at $837.6 \mathrm{~nm}$ $\left(4 p^{4} \mathrm{D}^{\mathrm{O}}{ }_{7 / 2} \rightarrow 4 s{ }^{4} \mathrm{P}_{5 / 2}\right)$ has the highest intensity and the intensity of this line increases linearly as the concentration of $\mathrm{Cl}$ increases from $2.5 \mathrm{mg} / \mathrm{m}^{2}$ to $25 \mathrm{mg} / \mathrm{m}^{2}$. Interference from the $\mathrm{Fe} I$ line at $838.8 \mathrm{~nm}$, as indicated in the gate width study [4], is no longer a major concern with a higher resolution of the spectrometer used, but the broadened line at $\sim 837.6 \mathrm{~nm}$ is still a result of interference with several $\mathrm{Fe}$ emission lines. It can also be seen in Fig. 7 (a) that the intensity of the Fe I lines from the laser-ablated plasma of the matrix and the $\mathrm{O} I$ lines from the partial ionization of the air (the most intense 

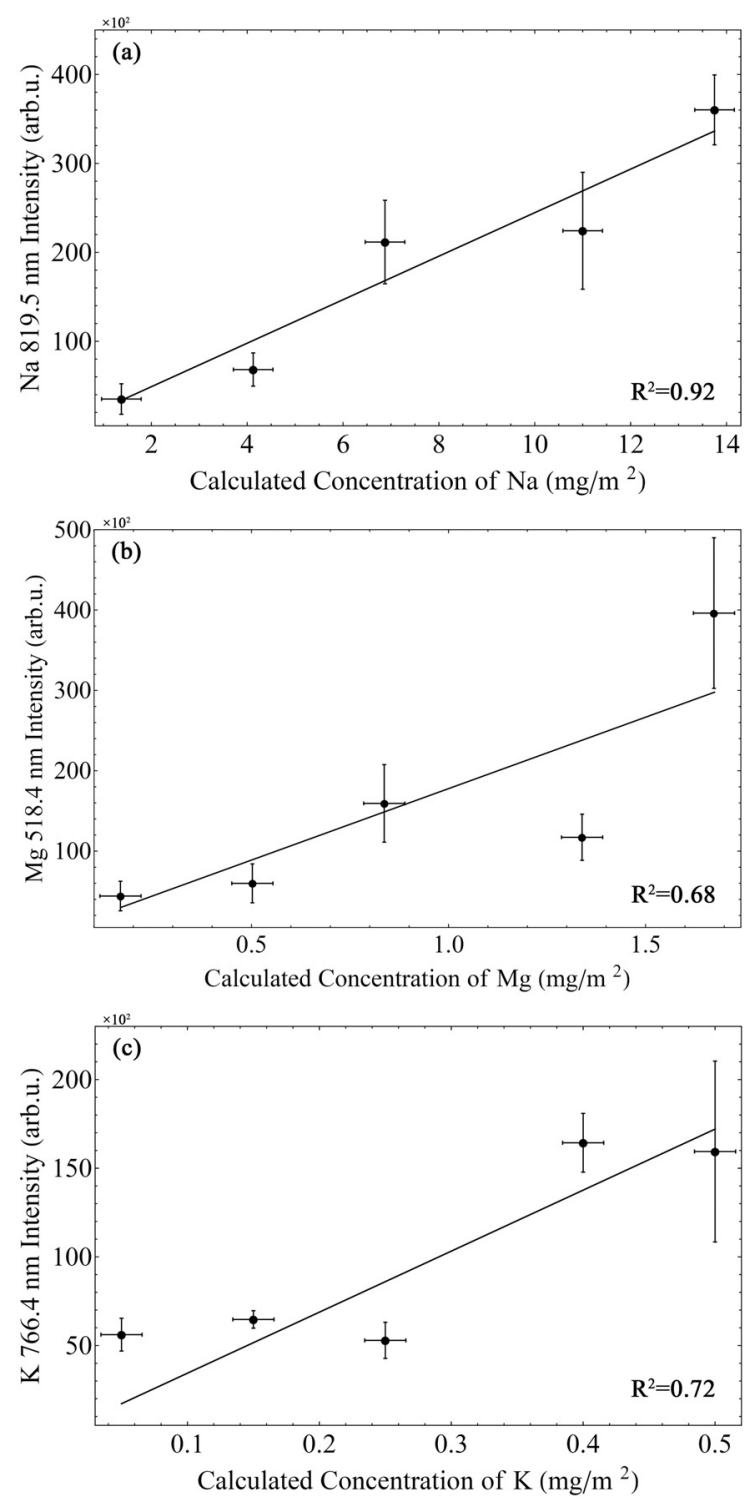

Figure 6: Dependence of (a) Na I (819 nm) emission intensity (peak area) on calculated $\mathrm{Na}$ concentration in the range of $1.4-13.8 \mathrm{mg} / \mathrm{m}^{2}$; (b) $\mathrm{Mg} \mathrm{I}(518 \mathrm{~nm}$ ) emission intensity (peak area) on calculated $\mathrm{Mg} 422$ concentration in the range of $0.17-1.67 \mathrm{mg} / \mathrm{m}^{2}$; (c) K I (766 nm) emission intensity (peak area) on calculated $\mathrm{K}$ concentration in the range of $0.05-0.5 \mathrm{mg} / \mathrm{m}^{2}$. The corresponding $\mathrm{Cl}$ concentrations in all plots are $2.5-25 \mathrm{mg} / \mathrm{m}^{2}$. The solid lines are linear regressions of the experimental data (solid circles). The vertical error bars is the standard 426 deviation of the emission intensities at 5 positions. The horizontal error bars derives from 3-s timing uncertainty in the sample preparation process. nal standards to reduce the experimental fluctuations of the emission intensity and the matrix effect typical for the LIBS technique [20]. A good linear correlation of the calibration curve with respect to $\mathrm{Cl}$ concentration $\left(R^{2}=0.92\right)$ has been obtained, as shown in Fig. 7 (b).
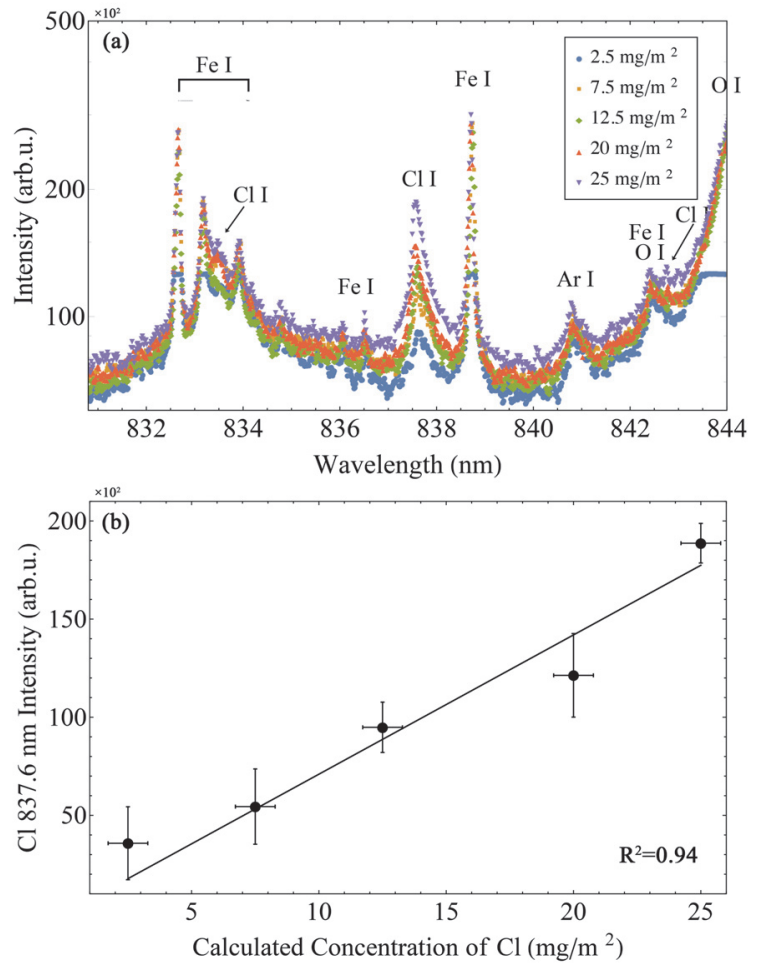

Figure 7: (a) Cl I accumulated emission spectrum (five position averaged) of the samples at $\mathrm{Cl}$ concentration in the range of $2.5-25 \mathrm{mg} / \mathrm{m}^{2}$; (b) dependence of the $\mathrm{Cl}$ I ( $837 \mathrm{~nm}$ ) emission intensity (peak area) on the calculated $\mathrm{Cl}$ concentration. The solid line is linear regression of the experimental data (solid circles). The vertical error bars represent the standard deviation of the emission intensities at 5 positions. The horizontal error bars originate from 3-s timing uncertainty in the sample preparation process. For interpretation of the references to color in this figure legend, reader is referred to the web version of this article.

Although $\mathrm{Cl}$ can be directly detected in the current LIBS measurement with open-beam delivery, it is difficult to further reduce the LOD. It is also difficult to conduct direct $\mathrm{Cl}$ measurements in the field environment characteristics for DCSS, where fiber transport of a high-power laser pulse is needed. This is because a high laser fluence (at least several $\mathrm{J} / \mathrm{cm}^{2}$ ) must be used to observe the $\mathrm{Cl}$ emission [2]. The input laser energy of even a large-diameter $(1 \mathrm{~mm})$ fiber is usually limited to $<30 \mathrm{~mJ}$, and the minimum focal spot size that can be obtained following transport through such highly multimode fiber increases linearly with fiber diameter.

On the other hand, quantitative measurement of alkali 
metals is important not only for the reason that those el- 484 ements could serve as surrogates for measurement of 485 total $\mathrm{Cl}$ concentration if the transport and speciation of ${ }_{486}$ salt is fully understood, but also because they indicate 487 the composition of the deposited salt $[18,21]$. Accord- 488 ing to Bryan et al. [21], the composition of deposits on 489 the SS canister is governed by the rate of deposition and 490 the rate of exchange or reaction with reactive gases in 491 the air, and could vary with location, time, and tempera- 492 ture. This composition determines the temperature and 493 relative humidity at which deliquescence of salt and thus 494 SCC can occur [21]. Further study on the influence of 495 matrix effects also requires the knowledge of deposited 496 salt composition.

\section{Conclusion and Perspective}

Because of the direct LIBS measurement of $\mathrm{Cl}$ is complicated by the high excitation energy of $\mathrm{Cl}$ which is 503 difficult to reach in LIBS delivered over an optical fiber, 504 we explored the potential for surrogate measurement of $\mathrm{Cl}$ in sea salt deposited on SS surfaces by detecting the associated alkali metal $\mathrm{Na}$, and assumed that the ratio of 505 its concentration to that of $\mathrm{Cl}$ remains constant during the laboratory sample preparation process. $\mathrm{Mg}$ and $\mathrm{K}, 506$ however, have not shown sufficient sensitivity to serve 507 as acceptable surrogates for $\mathrm{Cl}$ measurement at such 508 low concentration. Homogeneous salt deposits with 509 known concentrations on SS substrates were prepared 510 and characterized by SEM/EDS/IC for benchmarking the LIBS measurements. The ability to quantify $\mathrm{Cl}$ on SS in concentrations as low as $0.5 \mathrm{mg} / \mathrm{m}^{2}$ using the $\mathrm{Na}$ I line at $589.0 \mathrm{~nm}$ has been presented in the laboratory environment. The linear dynamic range of this reso- ${ }^{512}$ nance $\mathrm{Na}$ line extends over approximately two orders ${ }_{514}^{513}$ of magnitude in concentration down to $\lesssim 20 \mathrm{mg} / \mathrm{m}^{2}$. 515 Because of the interference with $\mathrm{Fe}$ and/or Ar emis- ${ }^{516}$ sion lines, K I (766.4 nm) and Mg I (518.4 nm) lines ${ }^{517}$ do not show such good correlation between the optical ${ }_{519}^{518}$ emission intensities and their calculated surface con- ${ }_{520}$ centrations at corresponding $\mathrm{Cl}$ concentrations in the ${ }^{521}$ range of $2.5-25 \mathrm{mg} / \mathrm{m}^{2}$. Samples were also character- ${ }^{522}$ ized using the $\mathrm{Na}$ I line at $819.5 \mathrm{~nm}$ and the $\mathrm{Cl}$ I line ${ }_{524}^{523}$ at $837.6 \mathrm{~nm}$ with comparable sensitivity with the reso- 525 nance $\mathrm{Na}$ line. Linear relationships between the inten- ${ }^{526}$ sities of $\mathrm{Na} \mathrm{I}(819.5 \mathrm{~nm})$ and $\mathrm{Cl} \mathrm{I}$ lines and their ${ }^{-{ }^{2}}{ }^{527}$ responding concentrations were found. Therefore, we ${ }_{529}^{528}$ conclude that the LIBS measurement of $\mathrm{Na}$ is an effec- ${ }^{530}$ tive way of quantifying $\mathrm{Cl}$ on SS at low concentrations ${ }^{531}$ (as low as $0.5 \mathrm{mg} / \mathrm{m}^{2}$ ) if the speciation and neutraliza- ${ }_{533}^{532}$ tion of salts are not of major concern, and may be a ${ }_{534}$ promising approach toward fiber-coupled LIBS for deployment in field conditions. Although there is a potential for the Na-to-Cl ratio to be altered in the transport to DCSS, the method could still reduce the rate of occurrence of false negatives and serve as a good surrogate for $\mathrm{Cl}$ detection when the effect of transport on the Na-to-Cl ratio is fully understood. The performance of surrogate measurement of $\mathrm{Cl}$ by $\mathrm{K}$ and $\mathrm{Mg}$, on the other hand, needs to be improved for obtaining more information about that component of sea salt deposition on the canister, and thus to even better understand matrix effect of LIBS detection and the process of $\mathrm{Cl}$-induced corrosion. For future work, surrogate measurement of $\mathrm{Cl}$ concentration on SS surfaces by alkali element detection will be integrated into fiber-coupled LIBS with compact devices for field measurement at DCSS facilities. While the difficulty of transmitting high-power laser pulses through optical fibers is noted, direct $\mathrm{Cl}$ measurement through fiber-coupled LIBS at low concentration is still highly valuable and may be partially addressed by use of double-pulse excitation.

\section{Acknowledgments}

This work has been funded by the Department of Energy's Nuclear Energy University Program award number DE-NE0008266, and in-part by the U.S. Department of Homeland Security under Grant Award Number 2012.05 DN-130-NF0001.

\section{References}

[1] T. M. Ahn, An approach to model abstraction of stress corrosion cracking damage in management of spent nuclear fuel and high-level waste, in: ASME 2013 Pressure Vessels and Piping Conference, American Society of Mechanical Engineers, pp. V06AT06A083-V06AT06A083.

[2] S. Eto, T. Fujii, Laser-induced breakdown spectroscopy system for remote measurement of salt in a narrow gap, Spectrochimica Acta Part B: Atomic Spectroscopy 116 (2016) 51-57.

[3] M. Wataru, H. Kato, S. Kudo, N. Oshima, K. Wada, H. Narutaki, Measurement of atmospheric sea salt concentration in the dry storage facility of the spent nuclear fuel, in: 14th International Conference on Nuclear Engineering, American Society of Mechanical Engineers, pp. 857-863.

[4] S. Eto, J. Tani, K. Shirai, T. Fujii, Measurement of concentration of chlorine attached to a stainless-steel canister material using laser-induced breakdown spectroscopy, Spectrochimica Acta Part B: Atomic Spectroscopy 87 (2013) 74-80.

[5] L. J. Radziemski, D. A. Cremers, Handbook of Laser Induced Breakdown Spectroscopy, John Wiley \& Sons, West Sussex, England, 2006.

[6] K. Hartig, J. Colgan, D. Kilcrease, J. Barefield II, I. Jovanovic, Laser-induced breakdown spectroscopy using mid-infrared femtosecond pulses, Journal of Applied Physics 118 (2015) 043107. 
[7] P. Ko, K. Hartig, J. McNutt, R. Schur, T. Jacomb-Hood, I. Jovanovic, Adaptive femtosecond laser-induced breakdown spectroscopy of uranium, Review of Scientific Instruments 84 (2013) 013104.

[8] S. Eto, T. Matsuo, T. Matsumura, T. Fujii, M. Y. Tanaka, Quantitative estimation of carbonation and chloride penetration in reinforced concrete by laser-induced breakdown spectroscopy, Spectrochimica Acta Part B: Atomic Spectroscopy 101 (2014) 245-253.

[9] E. Tognoni, V. Palleschi, M. Corsi, G. Cristoforetti, Quantitative micro-analysis by laser-induced breakdown spectroscopy: a review of the experimental approaches, Spectrochimica Acta Part B: Atomic Spectroscopy 57 (2002) 1115-1130.

[10] K. Hartig, J. McNutt, P. Ko, T. Jacomb-Hood, I. Jovanovic, Pulse chirp effects in ultrafast laser-induced breakdown spectroscopy, Journal of Radioanalytical and Nuclear Chemistry 296 (2013) 135-141.

[11] V. Detalle, M. Sabsabi, L. St-Onge, A. Hamel, R. Héon, Influence of Er:YAG and Nd:YAG wavelengths on laser-induced breakdown spectroscopy measurements under air or helium atmosphere, Applied optics 42 (2003) 5971-5977.

[12] C. Hanson, S. Phongikaroon, J. R. Scott, Temperature effect on laser-induced breakdown spectroscopy spectra of molten and solid salts, Spectrochimica Acta Part B: Atomic Spectroscopy 97 (2014) 79-85.

[13] K. Sugiyama, T. Fujii, T. Matsumura, Y. Shiogama, M. Yamaguchi, K. Nemoto, Detection of chlorine with concentration of $0.18 \mathrm{~kg} / \mathrm{m} 3$ in concrete by laser-induced breakdown spectroscopy, Appl. Opt. 49 (2010) C181-C190.

[14] J. Riley, M. Tongudai, The major cation/chlorinity ratios in sea water, Chemical Geology 2 (1967) 263-269.

[15] F. Culkin, R. Cox, Sodium, potassium, magnesium, calcium and strontium in sea water, in: Deep Sea Research and Oceanographic Abstracts, volume 13, Elsevier (1976), pp. 789-804.

[16] C. A. Pio, D. A. Lopes, Chlorine loss from marine aerosol in a coastal atmosphere, Journal of Geophysical Research: Atmospheres 103 (1998) 25263-25272.

[17] D. R. Hitchcock, L. L. Spiller, W. E. Wilson, Sulfuric acid aerosols and hcl release in coastal atmospheres: evidence of rapid formation of sulfuric acid particulates, Atmospheric Environment (1967) 14 (1980) 165-182.

[18] M. M. Tan, S. Cui, J. Yoo, S.-H. Han, K.-S. Ham, S.-H. Nam, Y. Lee, Feasibility of laser-induced breakdown spectroscopy (libs) for classification of sea salts, Applied Spectroscopy 66 (2012) 262-271.

[19] L. Sun, H. Yu, Correction of self-absorption effect in calibration-free laser-induced breakdown spectroscopy by an internal reference method, Talanta 79 (2009) 388-395.

[20] L. Zheng, S. Niu, A. Q. Khan, S. Yuan, J. Yu, H. Zeng, Comparative study of the matrix effect in cl analysis with laser-induced breakdown spectroscopy in a pellet or in a dried solution layer on a metallic target, Spectrochimica Acta Part B: Atomic Spectroscopy 118 (2016) 66-71.

[21] C. R. Bryan, D. G. Enos, Understanding the Environment on the Surface of Spent Nuclear Fuel Interim Storage Containers (No. SAND2013-8487C), Technical Report, Sandia National Laboratories (SNL-NM), Albuquerque, NM (United States), 2013. 